\title{
Assessment of Diabetic Control by Measurement of Urinary Glycopeptides
}

\author{
H. Vlassara, M. Brownlee, and A.Cerami \\ Laboratory of Medical Biochemistry, The Rockefeller University, New York, USA
}

\begin{abstract}
Summary. The relationship between improvement in diabetic control and changes in levels of glycosylated urinary peptides was investigated. Eight poorly controlled Type 1 (insulin-dependent) diabetic patients were studied as optimal metabolic control was achieved. Mean daily blood glucose values and weekly haemoglobin $\mathrm{A}_{1}$ levels were determined simultaneously. Urinary glycosylated peptide levels fell $50 \%$ in 15 days, compared with 23 days for haemoglobin $\mathrm{A}_{1}$. Levels of glycosylated urinary peptides were sensitive to increased mean blood glucose concentrations of $9.72 \mathrm{mmol} / 1$ and increased linearly up to $20.0 \mathrm{mmol} / 1(r=0.98)$ when compared with mean blood glucose levels obtained 8-9 days earlier. A similar correlation
\end{abstract}

was found with haemoglobin $A_{1}$ levels. Levels of glycosylated urinary peptides before and after optimal control were compared, and a decrease of $40 \%$ was observed (pre-control: $269 \pm$ $44 \mu \mathrm{mol} /$ day, optimal control: $162 \pm 45 \mu \mathrm{mol} /$ day, mean \pm SEM). The lag time between the fall in mean blood glucose level and the parallel fall in glycosylated urinary peptides was 8-9 days, suggesting that measurement of these compounds may become a useful clinical laboratory technique for monitoring short-term integrated glycaemia in diabetic patients.

Key words: Diabetic control, urine, glycopeptides, affinity chromatography, non-enzymatic glycosylation.
The introduction of glycosylated haemoglobin $\left(\mathrm{HbA}_{1 \mathrm{a}-\mathrm{c}}\right)$ measurement has greatly enhanced our ability to monitor and assess the effects of therapeutic adjustments on overall long-term blood glucose control, since glycohaemoglobin levels are dependent on the integrated mean blood glucose level and reflect the time-averaged blood glucose levels over the preceding weeks [1, 2]. Glycohaemoglobin levels take 4-6 weeks to become normal after the establishment of euglycaemia, because of the 120 day life span of haemoglobin in the circulating erythrocyte. For this reason, indicators of shorter-term integrated glycaemia may have greater clinical utility, since they would have a shorter lag in response time.

Previous studies from this laboratory [3] have shown that levels of urinary glycosylated peptides and amino acids, thought to be the breakdown products of various glycosylated proteins, were significantly higher in diabetic, as opposed to normal, patients. In this report, we describe the relationship between improvement in metabolic control and reduced levels of these urinary compounds.

\section{Methods}

Eight poorly controlled Type 1 (insulin-dependent) non-ketotic diabetic patients (five females and three males, aged 16-60 years) were admitted to the Rockefeller Hospital Clinical Research Center. For the first week of the study, all patients were maintained on their customary insulin regimen and diet. For the remainder of the study, all patients were placed on a standard American Diabetes Association diet ( $40 \%$ fat) calculated to maintain body weight (25-30 calories $\cdot \mathrm{kg}^{-1} \cdot \mathrm{day}^{-1}$ ) [4] and exercise, while their insulin regimen was adjusted by using a multiple daily injection system in conjunction with patient-monitored glucose measurement (before and $1 \mathrm{~h}$ after each meal and at bedtime) until optimal metabolic control (mean daily blood glucose values $<8 \mathrm{mmol} / \mathrm{l}$ ) was achieved. Each patient's level of metabolic control was assessed by multiple daily blood glucose determinations with Stat-Tek glucose analyzers (Bio-Dynamics, Indianapolis, Indiana. USA) before and $1 \mathrm{~h}$ after each meal and before bedtime. Weekly blood samples were obtained for $\mathrm{HbA}_{1}$ levels (total fast haemoglobin fraction), determined by using pre-packaged cation-exchange columns (Helena Laboratories, Beaumont, Texas, USA). Urine samples ( $24 \mathrm{~h}$ ) were collected in toluene $(10 \mathrm{ml})$ from all patients daily for the entire period in hospital and from eight normal subjects, aged $20-40$ years. Urinary electrolytes, glucose, total protein, and creatinine clearance were determined daily by standard clinical laboratory methods. Aliquots of these $24 \mathrm{~h}$ urine samples $(0.40 \%$ of total volume $)$ were either analyzed immediately for glycosylated peptides or stored at $-70^{\circ} \mathrm{C}$ until the time of analysis [3]. Each urine sample was adjusted to $\mathrm{pH} 9.0$ with $1.0 \mathrm{~mol} / \mathrm{I} \mathrm{NaOH}$, then shaken for $15 \mathrm{~s}$ on a Vortex electric mixer (Fisher Scientific Industries, Springfield, New Jersey, USA) and centrifuged for $5 \mathrm{~min}$ at $12,000 \times \mathrm{g}$ to remove insoluble material. The supernatant was transferred to a $1.5 \mathrm{~cm}$ $\times 14 \mathrm{~cm}$ column containing m-amino-phenyl boronic acid immobilized on Bio-Gel P- 6 previously equilibrated with $0.025 \mathrm{~mol} / 1$ sodium phosphate buffer ( $\mathrm{pH} 9.0)$. Fractions $(4.0 \mathrm{ml})$ were collected at a flow rate of $20 \mathrm{ml} / \mathrm{h}$. After 100 fractions were collected, the buffer was removed and the column eluted with $0.025 \mathrm{~mol} / 1 \mathrm{HCl}$. Aliquots $(200 \mu \mathrm{l})$ from each fraction were assayed for the presence of ninhydrin-positive material using the method of Moore and Stein [5]. The $\Sigma \AA_{570}$ was calculated for each peak and compared with the $A_{570}$ of a leucine standard 


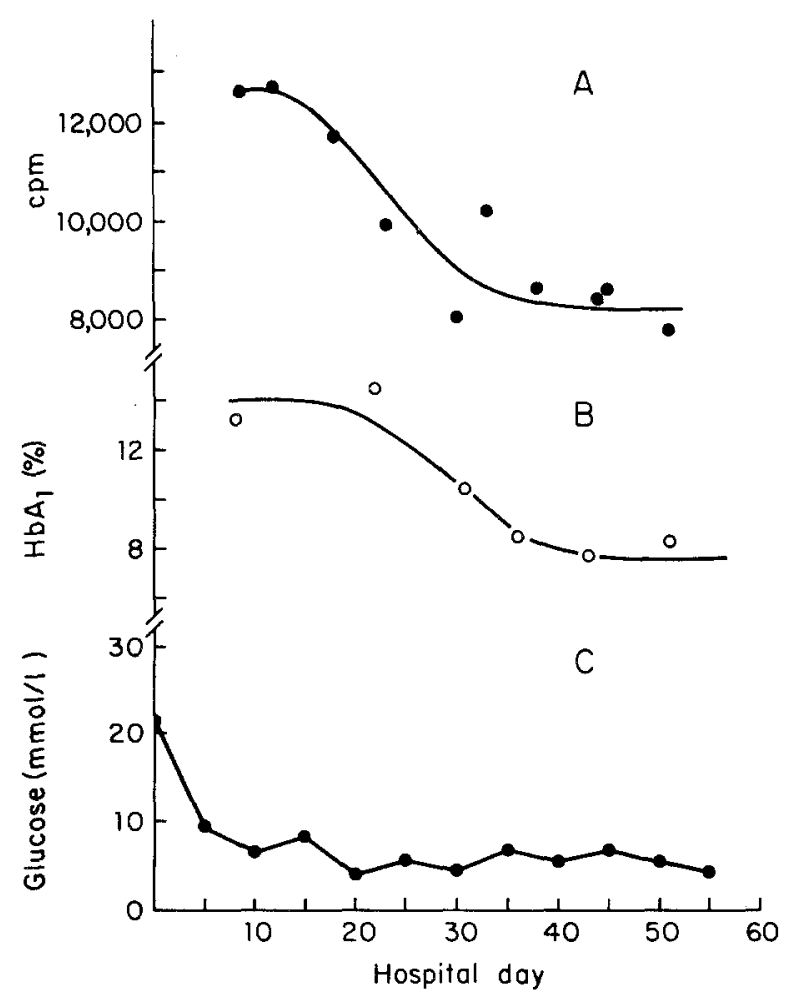

Fig. 1. Temporal correlations of changes in a representative patient's non-enzymatically glycosylated urinary peptides $(A)$, haemoglobin $\mathrm{A}_{\text {tal- }}(B)$ and mean daily blood glucose concentration $(C)$ over a 55-day period in hospital. Euglycaemia was established after 1 week of poor control

curve obtained concurrently. The amount of non-enzymatically glycosylated compounds secreted during $24 \mathrm{~h}$ was expressed as $\mu \mathrm{mol}$ of leucine equivalent. Ninhydrin-positive $\mathrm{HCl}$ elution peaks from one patient's samples were subsequently subjected to $\mathrm{NaB}_{3} \mathrm{H}_{4}$ reduction and acid hydrolysis in order to establish the precise temporal relationship between reduction in levels of non-enzymatically glycosylated urinary peptides and improvement in diabetic control. The hydrolysates were applied to columns containing $5 \mathrm{ml}$ of $\mathrm{AG} 50 \mathrm{~W}-\mathrm{X} 4,-400$ mesh $(\mathrm{H}+$ form). Columns were washed with water until the free sugars and $\mathrm{NaB}_{3} \mathrm{H}_{4}$ were removed, then eluted with $1.5 \mathrm{~mol} / 1 \mathrm{NH}_{4} \mathrm{OH}$. Ammonia was removed by evaporation, and the amino acids were re-chromatographed on m-amino-phenyl boronic acid columns described above to remove traces of non-glycosylated radioactive contaminants. Amino acid analysis of the concentrated $\mathrm{HCl}$ elution peaks was performed on a Beckman Model $119 \mathrm{C}$ amino acid analyzer with stream division ( $90 \%$ to the fraction collector, $1.0 \mathrm{ml}$ fractions). Aliquots $(500 \mu \mathrm{l})$ were counted in $7.0 \mathrm{ml}$ of hydrofluor (National Diagnostic, Sommerville, New Jersey, USA), and the elution patterns were compared with chromatograms of reduced and hydrolyzed glycosylated amino acid standards. From this, the total amount of glycosylated amino acid radioactivity was determined.

\section{Results}

Within the first 5 days of adjusted therapeutic regimen, optimal metabolic control was achieved, as evidenced by the decline of mean daily blood glucose to normal levels. This was followed by a decrease of $\mathrm{HbA}_{1}$ (fast fraction) to normal range $(5.4 \%-8.9 \%)$ within 4 weeks. After eugly-

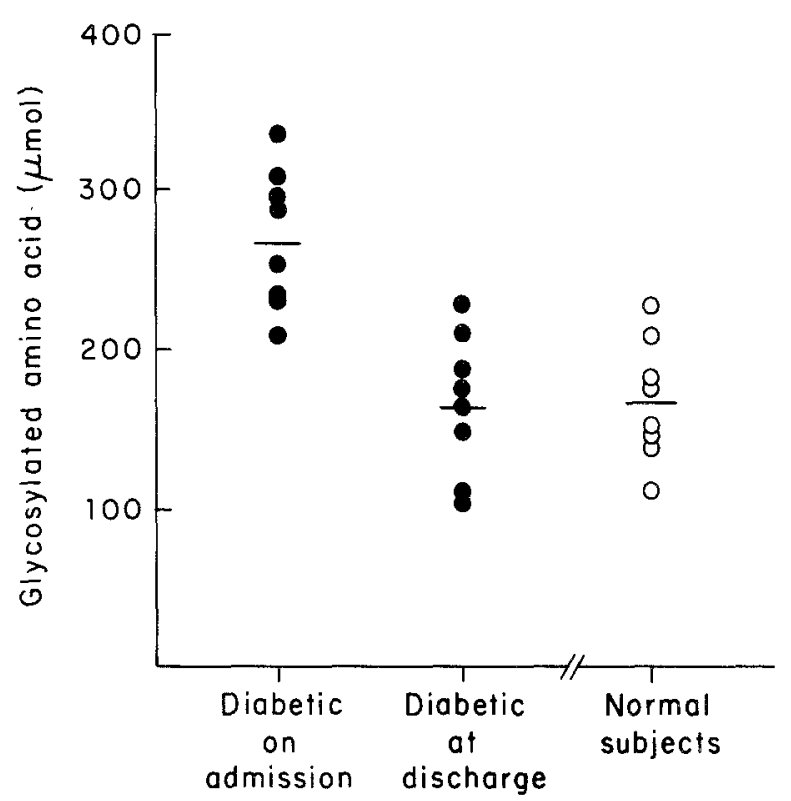

Fig. 2. Levels of ninhydrin-positive glycosylated amino acids and peptides in urine from uncontrolled diabetic patients (day of admission), well controlled diabetic patients (day of discharge) and normal subjects, expressed as $\mu \mathrm{mol}$ leucine-equivalent glycosylated amino acid/ day. The mean is indicated for each group, with $p<0.001$ between the first and the second two groups

caemia was achieved, glycosylated urinary peptide levels decreased with a decay curve parallel to that of $\mathrm{HbA}_{1}$, but displaced to the left. From Figure 1, it can be seen that $50 \%$ of the fall in levels of urinary glycosylated peptides occurred over 15 days, compared with 23 days for $\mathrm{HbA}_{1}$. Amino acid analysis of $\mathrm{NaB}_{3} \mathrm{H}_{4}$-reduced hydrolysates of the $\mathrm{HCl}$ peaks showed that glycosylated lysine was the major borohydride-reducible adduct present in both diabetic and normal subjects.

The relationship between levels of glycosylated urinary peptides and mean blood glucose was determined by calculating mean blood glucose values from all measurements taken before and $1 \mathrm{~h}$ after each meal and at bedtime 8 or 9 days before a given urine analysis. Linear regression analysis reveals a clear correlation between these two parameters $(r=0.98)$. A similar relationship was demonstrated beween levels of urinary glycosylated peptides and $\mathrm{HbA}_{1},(r=0.76)$.

Levels of glycosylated peptides in urine from uncontrolled diabetic patients (day of hospital admission) were compared with levels found when optimal control had been established for a minimum of 4 weeks (Fig. 2). A decrease of $39.8 \%$ was observed over this period ( $269 \pm 44$ versus $162 \pm 45 \mu \mathrm{mol} /$ day, mean \pm SEM), with diabetic patients' values at discharge identical to those from control subjects. 


\section{Discussion}

Clinical tests that indicate the degree of long-term integrated glycaemia, primarily measurements of glycohaemoglobin levels, are used to complement home blood or urine glucose monitoring, which reflect only daily glycaemic patterns. These glycohaemoglobin levels, however, take 4-6 weeks to become normal after the establishment of euglycaemia. Because of this, indicators of shorter-term integrated glycaemia have been sought which would have a shorter lag in response time. Glycosylated plasma proteins have been investigated in this regard, and glycosylated albumin has been shown to be one such shorter-term indicator of integrated glycaemia $[6,7]$.

In the present study, we have demonstrated that glycosylated urinary peptides and amino acids, isolated by a previously described technique [3], are also an indicator of shorter-term integrated glycaemia. Fifty percent of the fall in levels of urinary glycosylated peptides occurs over a 2-week period (Fig.1), an interval comparable with that described for glycosylated albumin [6] and considerably shorter than that reported for glycohaemoglobins [1].

Levels of glycosylated urinary peptides are sensitive to increased mean blood glucose concentrations of $9.72 \mathrm{mmol} / 1$ and increase linearly up to mean blood glucose values of $20 \mathrm{mmol} / 1$. An extremely high correlation coefficient $(0.98)$ was observed when levels of glycosylated urinary peptides were compared with mean blood glucose values obtained 8-9 days previously. From these data, the lag time between the fall in levels of mean blood glucose and the parallel fall in those of glycosylated urinary peptides appears to be of the order of 1 week. The measurement of glycosylated peptides in urine may thus become a useful clinical laboratory technique for monitoring short-term integrated glycaemia in diabetic patients. Adoption of a batch elution procedure would reduce the complexity of this assay to the level of cationexchange column techniques currently employed for the determination of glycosylated haemoglobin levels.
However, the requirement of $24 \mathrm{~h}$ urine specimens does limit feasibility to clinical situations where these can be obtained.

Acknowledgements. We would like to thank A.Checchi and K. McDermott for skilled technical assistance. Dr. Vlassara is the recipient of a Juvenile Diabetes Fellowship (No.79F134) and a Research Scientist Development Award (1-K01-AG 00148-01) from the National Institute of Arthritis, Metabolism, and Digestive Diseases and the National Institute of Aging. Dr. Brownlee is the recipient of a Special Emphasis Research Career Award (1-K01-AM 000589-01 SRC) from the National Heart, Lung, and Blood Institute and the National Institute of Arthritis, Metabolism, and Digestive Diseases. This work was supported in part by a grant from Akzona, Asheville, North Carolina, USA.

\section{References}

1. Koenig RJ, Peterson CM, Jones RL, Saudek C, Lehrman M, Cerami $A$ (1976) Correlation of glucose regulation and hemoglobin $A_{1 c}$ in diabetes mellitus. N Engl J Med 295: 417-420

2. Koenig RJ, Cerami A (1980) Hemoglobin $A_{1 c}$ and diabetes mellitus. Ann Rev Med 31:29-34

3. Brownlee M, Vlassara H, Cerami A (1980) Measurement of glycosylated amino acids and peptides from urine of diabetic patients using affinity chromatography. Diabetes 29: 1044-1047

4. Crapo PA (1981) Dietary modifications in the management of diabetes. In: Brownlee M, (ed) Diabetes Mellitus, vol V. Garland STPM Press, New York, pp 41-74

5. Moore S, Stein WH (1954) A modified ninhydrin reagent for the photometric determination of amino acids and related compounds. J Biol Chem 211: 907-913

6. Dolhofer R, Wieland OH (1980) Increased gylcosylation of serum albumin in diabetes mellitus. Diabetes 29:417-422

7. McFarland KF, Catalano EW, Day JF, Thorpe SR, Baynes JW (1979) Nonenzymatic glycosylation of serum proteins in diabetes mellitus. Diabetes 28: 1011-1013

Received: 9 October 1981

and in revised form: 29 March 1982

Dr. Helen Vlassara

Laboratory of Medical Biochemistry

The Rockefeller University

1230 York Avenue

New York, New York 10021, USA 